\title{
Communication
}

\section{Structure of an Archaeal RNA Polymerase}

\author{
Anselm G. Kusser ${ }^{1} \dagger$, Michela G. Bertero ${ }^{1} \dagger$, Souad $\mathrm{Naji}^{2}$ \\ Thomas Becker ${ }^{1}$, Michael Thomm ${ }^{2}$, Roland Beckmann ${ }^{1}$ \\ and Patrick Cramer ${ }^{1 *}$
}

\author{
${ }^{1}$ Gene Center Munich and \\ Center for integrated Protein \\ Science CiPSM \\ Department of Chemistry \\ and Biochemistry, Ludwig- \\ Maximilians-Universität \\ München, Feodor-Lynen-Str. 25 \\ 81377 Munich, Germany \\ ${ }^{2}$ Institut für Biochemie \\ Genetik und Mikrobiologie \\ Universität Regensburg \\ Universitätsstr. 31 \\ 93053 Regensburg, Germany
}

Received 30 June 2007; received in revised form 24 August 2007; accepted 28 August 2007 Available online 5 September 2007

\section{Edited by R. Huber}

Related multisubunit RNA polymerases (RNAPs) carry out gene transcription in all kingdoms of life. Since structural information is limited to bacterial and eukaryotic RNAPs, we determined the cryo-electron microscopic structure of the RNAP from the thermophilic archaeon Pyrococcus furiosus at $13 \AA$ resolution. Comparison with eukaryotic RNAP II reveals a conserved architecture, no homologues for subunits Rpb8 and Rpb9, and significant deviation in the polymerase foot, jaws, pore, and protrusion. The structural organization of the archaeal RNA polymerase serves as a reference for future structure-function analysis of the transcription mechanism and allows for evolutionary comparisons.

(C) 2007 Published by Elsevier Ltd.

Keywords: multisubunit cellular RNA polymerase; gene transcription; archaeal gene expression; cryo-electron microscopy; homology modelling
Unravelling the mechanisms of gene transcription and its regulation requires detailed structural information for the key enzymes of transcription, the multisubunit RNA polymerases (RNAPs). Bacteria and archaea contain a single RNAP, and eukaryotes contain three RNAPs, RNAP I, RNAP II and RNAP III. Crystallographic structures are available for bacterial RNAP and the eukaryotic RNAP II, ${ }^{1-5}$ which reveal a conserved core architecture and

${ }^{*}$ Corresponding author. E-mail address: cramer@LMB.uni-muenchen.de.

$\uparrow$ A.G.K. and M.G.B. contributed equally to this work.

Present address: M. G. Bertero, Centre for Genomic Regulation CRG, Systems Biology Programme, Dr. Aiguader 88, 08003 Barcelona, Spain.

Abbreviations used: RNAP, RNA polymerase; P.fu, Pyrococcus furiosus; EM, electron microscopy; TBP, TATA box-binding protein; TF, transcription factor; FSC, Fourier shell correlation. active centre cleft. ${ }^{6}$ However, no structural information is available for archaeal RNAPs, except for the small polymerase subcomplex $\mathrm{F} / \mathrm{E}^{\prime},{ }^{7}$ the counterpart of the RNAP II subcomplex Rpb4/7. Sequence analysis suggested that archaeal RNAPs are related to eukaryotic RNAP II more closely than they are to bacterial RNAP. ${ }^{8}$ Archaeal homologues are known for all RNAP II subunits except Rpb8 and Rpb9 (Table 1). ${ }^{9}$ The similarity between the archaeal and eukaryotic RNAP II transcription machineries extends to the archaeal initiation factors TBP, TFB, and TFE, which are structural and functional counterparts of the eukaryotic factors TBP, TFIIB and the large subunit of TFIIE, respectively. ${ }^{10-13}$

To tackle the archaeal RNAP structure, we established a large-scale purification protocol for the endogenous polymerase from Pyrococcus furiosus (P.fu) based on a published method (Figure 1(a)). ${ }^{14}$ The improved protocol enabled purification of $5 \mathrm{mg}$ of RNAP from $60 \mathrm{~g}$ of P.fu cells. Pure RNAP comprised all subunits in an apparently stoichiometric 
Table 1. P.fu RNAP subunits in comparison to RNAP II

\begin{tabular}{|c|c|c|c|c|}
\hline Polymerase part & P.fu subunit & $M(\mathrm{kDa})$ & Corresponding Pol II subunit & Sequence identity $^{\mathrm{a}}(\%)$ \\
\hline \multirow[t]{11}{*}{ Core } & $\mathrm{A}^{\prime}$ & 103.1 & Rpb1 N-term. Part & 42.2 \\
\hline & $\mathrm{A}^{\prime \prime}$ & 44.4 & Rpb1 C-term. Part & 37.0 \\
\hline & B & 127.0 & $\mathrm{Rpb} 2$ & 43.2 \\
\hline & $\mathrm{D}$ & 29.8 & Rpb3 & 26.8 \\
\hline & $\mathrm{H}$ & 9.2 & Rpb5 & 40.2 \\
\hline & K & 6.2 & Rpb6 & 42.1 \\
\hline & - & - & Rpb8 & - \\
\hline & - & - & Rpb9 & - \\
\hline & $\mathrm{N}$ & 7.8 & Rpb10 & 52.3 \\
\hline & $\mathrm{L}$ & 11.1 & Rpb11 & 30.5 \\
\hline & $\mathrm{P}$ & 5.8 & Rpb12 & 36.7 \\
\hline \multirow[t]{2}{*}{ Subcomplex Rpb4/7 } & $E^{\prime}$ & 21.7 & Rpb7 & 22.2 \\
\hline & $\mathrm{F}$ & 14.1 & $\mathrm{Rpb} 4$ & 5.0 \\
\hline Total & - & 380.2 & - & 38.2 \\
\hline
\end{tabular}

${ }^{\text {a }}$ Number of amino acid residues in the P.fu RNAP subunit that are identical in the corresponding RNAP II subunit divided by the total number of residues in the P.fu RNAP subunit.

Figure 1. Cryo-EM structure of P.fu RNAP. (a) SDS-PAGE analysis of purified endogenous P.fu RNAP. P.fu cells were thawed by resuspending $60 \mathrm{~g}$ in $50 \mathrm{mM}$ Tris- $\mathrm{HCl}(\mathrm{pH}$ 8.0), $100 \mathrm{mM} \mathrm{KCl}, 10 \mathrm{mM} \mathrm{MgCl}$, 20\% (v/v) glycerol, $10 \mathrm{mM}$ $\beta$-mercaptoethanol, $1 \%$ Protease Inhibitor Cocktail $(0.28 \mu \mathrm{g}$ Leupeptin, $1.37 \mu \mathrm{g}$ pepstatin A, $0.17 \mathrm{mg}$ Phenylmethylsulfonylchloride, $0.33 \mathrm{mg}$ benzamidine per $1 \mathrm{ml}$ of $50 \%$ ethanol) at $4{ }^{\circ} \mathrm{C}$ over night, while stirring. An Emulsiflex (Avestin Emulsiflex C5) was used for cell disruption, applying 2 pressure cycles at $1000-1500 \mathrm{bar}\left(1 \mathrm{bar}=10^{5} \mathrm{~Pa}\right)$. To ensure complete cell lysis, a small aliquot was checked by phase-contrast microscopy. The lysate was centrifuged (30 min at $11.532 \mathrm{~g}$, Sorvall SLA-1500) and then centrifuged (90 min at $124.894 \mathrm{~g}$, Beckman Ti 45), recovering the supernatant after each step. The supernatant was loaded onto a column (GE Healthcare XK50) packed with $\sim 400 \mathrm{ml}$ of Biorex resin equilibrated with $50 \mathrm{mM}$ Tris- $\mathrm{HCl}$ (pH 8.0), $100 \mathrm{mM} \mathrm{KCl}, 2.5 \mathrm{mM} \mathrm{MgCl} 2,1 \mathrm{mM}$ EDTA, $10 \%$ (v/v) glycerol, $10 \mathrm{mM} \beta$-mercaptoethanol, $1 \%$ Protease Inhibitor Cocktail. The P.fu RNAP was eluted with $50 \mathrm{mM}$ Tris- $\mathrm{HCl}$ (pH 8.0), $1 \mathrm{M} \mathrm{KCl}, 2.5 \mathrm{mM} \mathrm{MgCl}_{2}, 1 \mathrm{mM}$ EDTA, $10 \%$ glycerol, $10 \mathrm{mM} \beta$-mercaptoethanol, $1 \%$ Protease Inhibitor Cocktail using a gradient of $0.1 \mathrm{M}-1 \mathrm{M} \mathrm{KCl}$. The fractions were subjected to a non-specific transcriptional activity test. P.fu RNAP eluted at $0.55-0.8 \mathrm{M} \mathrm{KCl}$. RNAP-containing fractions were pooled, dialysed against $50 \mathrm{mM}$ Tris- $\mathrm{HCl}(\mathrm{pH} 8.0), 100 \mathrm{mM} \mathrm{KCl}, 2.5 \mathrm{mM} \mathrm{MgCl}, 10 \%$ glycerol, $10 \mathrm{mM}$-mercaptoethanol and then loaded onto a Heparin column (20 ml HiPrep 16/10 Heparin FF) that was equilibrated with $50 \mathrm{mM} \mathrm{Tris-} \mathrm{HCl}(\mathrm{pH}$ 7.5), $100 \mathrm{mM} \mathrm{KCl}, 2.5 \mathrm{mM} \mathrm{MgCl}_{2}, 10 \%$ glycerol, $1 \mathrm{mM} \beta$-mercaptoethanol. The polymerase was eluted with $50 \mathrm{mM} \mathrm{Tris- \textrm {HCl }}$ (pH 7.5), $1 \mathrm{M} \mathrm{KCl}, 2.5 \mathrm{mM} \mathrm{MgCl}_{2}, 10 \%$ glycerol, $1 \mathrm{mM} \beta$-mercaptoethanol with a gradient of $0.1 \mathrm{M}-1 \mathrm{M} \mathrm{KCl}$. The fractions were checked for transcription activity. P. fu RNAP eluted between $0.17 \mathrm{M}$ and $0.42 \mathrm{M} \mathrm{KCl}$. RNAP-containing fractions were centrifuged (30 min, 12,000 rpm, Sorvall SLA-1500), diluted to $150 \mathrm{mM} \mathrm{KCl}$, and loaded onto a MonoQ Column (GE Healthcare) equilibrated with $50 \mathrm{mM}$ Tris- $\mathrm{HCl}(\mathrm{pH} 8.0), 100 \mathrm{mM} \mathrm{KCl}, 2.5 \mathrm{mM} \mathrm{MgCl}, 10 \%$ glycerol, $10 \mathrm{mM}$ mercaptoethanol. RNAP was eluted with $50 \mathrm{mM}$ Tris- $\mathrm{HCl}(\mathrm{pH} 8.0), 1 \mathrm{M} \mathrm{KCl}, 2.5 \mathrm{mM} \mathrm{MgCl}, 10 \%$ glycerol, $10 \mathrm{mM} \beta-$ mercaptoethanol using a gradient of $0.15 \mathrm{M}-1 \mathrm{M} \mathrm{KCl}$. The enzyme eluted between $0.32 \mathrm{M}$ and $0.37 \mathrm{M} \mathrm{KCl}$. RNAP-containing fractions were checked for purity by SDS-PAGE. The enzyme was further purified on a Superose 6 size-exclusion column (GE Healthcare) in $10 \mathrm{mM}$ Hepes (pH 7.0), $150 \mathrm{mM} \mathrm{KCl}, 2.5 \mathrm{mM} \mathrm{MgCl}, 5 \mathrm{mM}$ DTT. (b) Negative stain image of P.fu RNAP particles (top), and cryo-EM micrograph with particles indicated by circles (bottom). Purified P.fu RNAP was concentrated to $0.1 \mathrm{mg} / \mathrm{ml}$ and applied to carbon-coated holey grids (Quantifoil R3/3). Micrographs were recorded with a low dose of $25 \mathrm{e} /$ $\AA^{2}$ on a Tecnai Polara F30 field emission gun microscope at $300 \mathrm{kV}$ and scanned on a Heidelberg drum scanner with a pixel size of $1.23 \AA$ A on the object scale. The contrast transfer function was determined using CTFFIND and SPIDER. ${ }^{20}$ Particles were picked automatically with SIGNATURE, ${ }^{21}$ followed by visual inspection. The data were processed using SPIDER ${ }^{20}$ Initially 41,669 particles from 23 micrographs were aligned using as a reference a version of the complete Pol II structure 5 that was modified based on sequence homology and filtered to $25 \AA$ resolution. In the initial reference structure, the Rpb1 foot was deleted. During early refinement, density for a smaller foot appeared. This observation, together with several densities that appeared at positions where P.fu RNAP contains sequence insertions, indicated that the volumes were free of reference bias. Particles were sorted into subsets according to different clamp conformations, which was essential for reaching high resolution. For the first round of sorting, we used the current reconstructed volume (group I), and a volume obtained from a PDB file that corresponded to the initially used reference but contained the clamp domain in an entirely closed conformation (group II) that is observed for RNAP I. ${ }^{22}$ Each particle was aligned to both references, the two corresponding crosscorrelation coefficients were calculated, and the particle was assigned to the reference that yielded the higher coefficient. The particles were back-projected separately for each group, and the resulting volumes were used as group I and II reference volumes for the next round of sorting. The process was repeated several times until convergence was reached for the numbers of particles assigned to each group. This resulted in 22,240 particles with a closed clamp conformation, ${ }^{5}$ and 19,429 particles with other clamp conformations. The resolution for the group I volume was $16.8 \AA$ based on a cut-off value of 0.5 for the Fourier shell correlation. The group I volume was further refined to a resolution of $13 \AA$ (cf. (e)). (c) Five representative projection averages (out of a total of 83, top) and corresponding re-projections (bottom). (d) Cryo-EM density of P.fu RNAP (orange) with fitted X-ray structure of S. cerevisiae RNAP II (blue ribbon model). ${ }^{5}$ The views are from the front (left) and from the side (right). ${ }^{2}$ (e) Fourier shell correlation (FSC) function curve. The resolution is estimated to be around $13 \AA$ based on the 0.5 FSC cut-off criterion. (f) Gallery of regions of the P.fu RNAP structure deviating from yeast RNAP II (cf. Figure 2). Depicted domains in RNAP II are highlighted using the original RNAP II colour code. ${ }^{2,5}$ 

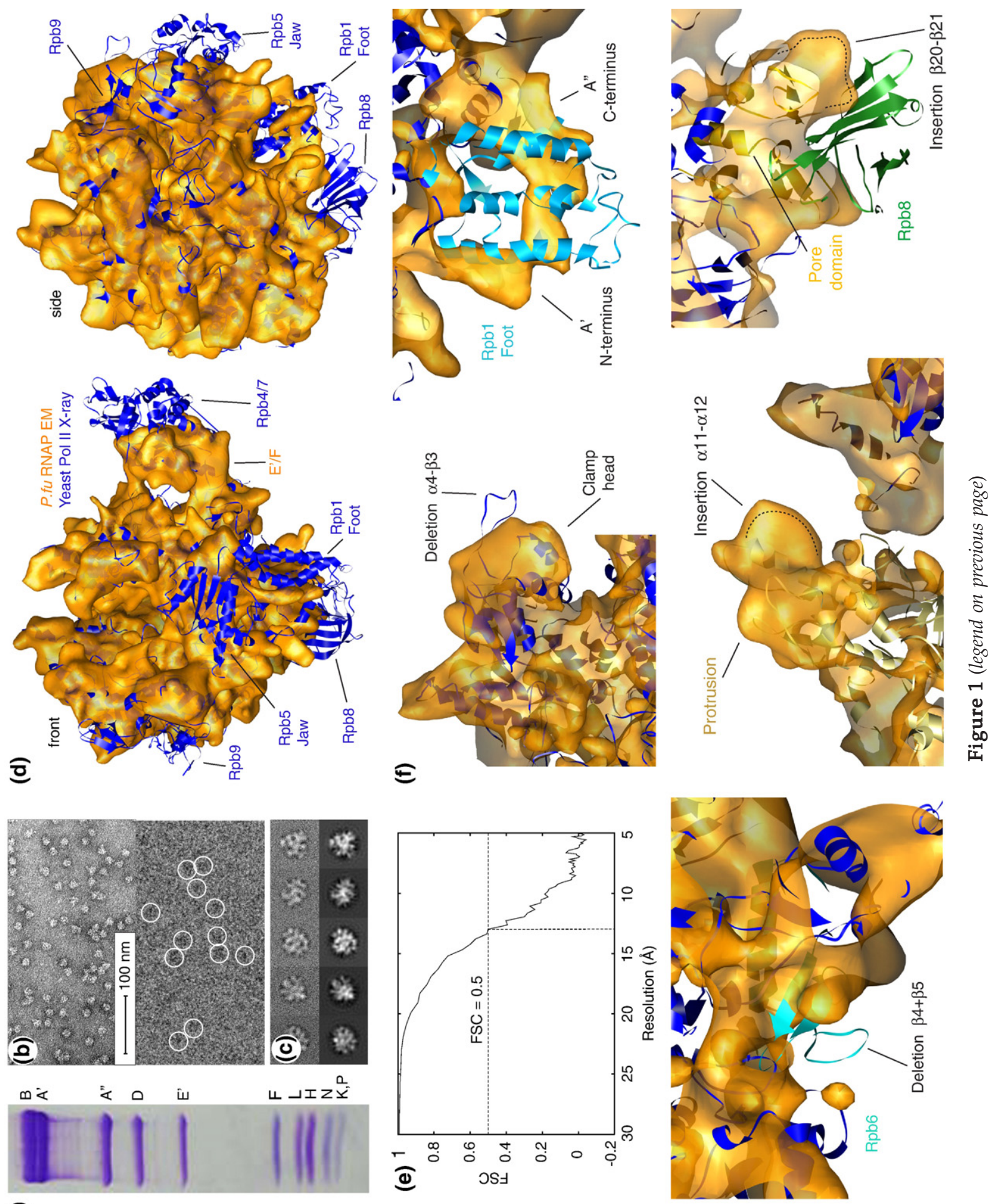
manner (Figure 1(a)). RNAP preparations were monodisperse and catalytically active (data not shown), and contained single particles according to electron microscopy (EM) with negative staining, and enabled collection of high-quality cryo-EM data (Figure 1(b)). The cryo-EM reconstruction with 22,240 conformationally uniform particles led to a map at $13 \AA$ resolution (Figure $1(\mathrm{~d})-(\mathrm{f})$ ).

The detailed EM map for P.fu RNAP enabled a unique fit of the crystal structure of the complete 12 subunit Saccharomyces cerevisiae RNAP II (Figure 1(d)). ${ }^{5}$ Comparison of the EM map with the RNAP II structure confirmed the overall conservation of the enzyme architecture and active centre, including the polymerase bridge helix, the pore, and the clamp. Outside the active centre, at least one functional surface is conserved. The dock domain and its surrounding regions are highly similar in P.fu RNAP and RNAP II, reflecting a conserved interaction with the initiation factor TFB/TFIIB. ${ }^{15,16}$ No density was present at the locations for the RNAP II subunits Rpb8 and Rpb9 (Figure 1(d) and (f)), consistent with a lack of archaeal homologues for these subunits.

To explain the observed differences between the EM map and the RNAP II structure, we constructed an RNAP II-based homology model for P.fu RNAP (Figure 2; Supplementary Data Figure S1). In the model, the regions with the highest level of sequence conservation cluster around the active centre cleft. Many peripheral regions are also conserved, and only several surface domains are divergent. In particular, the archaeal subunit $\mathrm{A}^{\prime}$, which is homologous to the N-terminal part of the largest RNAP II subunit Rpb1, contains a deletion in the clamp head, an extended pore domain, and it largely lacks the foot domain (Figures 1(f) and 2). In subunit $A^{\prime \prime}$, which is homologous to the C-terminal part of Rpb1, several loops in the jaw domain are shorter, and the $\mathrm{C}$-terminal repeat domain is missing. The $\mathrm{C}$ terminus of $\mathrm{A}^{\prime}$ and the $\mathrm{N}$ terminus of $\mathrm{A}^{\prime \prime}$ form residual structure in the region of the Rpb1 foot (Figures 1(f) and 2). Subunit B contains an eight-residue insertion in the Rpb2 protrusion domain (Figures 1(f) and 2).

Among the small archaeal subunits, D and L resemble the RNAP counterparts Rpb3 and Rpb11, respectively, except that several surface loops are missing, including the zinc loop in Rpb3 (Figure 2). Subunit H lacks the N-terminal jaw domain present in its eukaryotic counterpart Rpb5 (Figure 1(d)). Subunit $\mathrm{K}$ lacks the N-terminal region of the counterpart Rpb6, and the last two $\beta$-strands in the C-terminal assembly domain of Rpb6 (Figure 1(f)). Consequently, subunit $\mathrm{K}$ closely resembles the bacterial RNAP subunit homolog $\omega .{ }^{17}$ The heterodimeric subcomplex $\mathrm{F} / \mathrm{E}^{\prime}$ is situated at the expected surface position that is occupied by its counterpart

$A^{\prime}$

A"

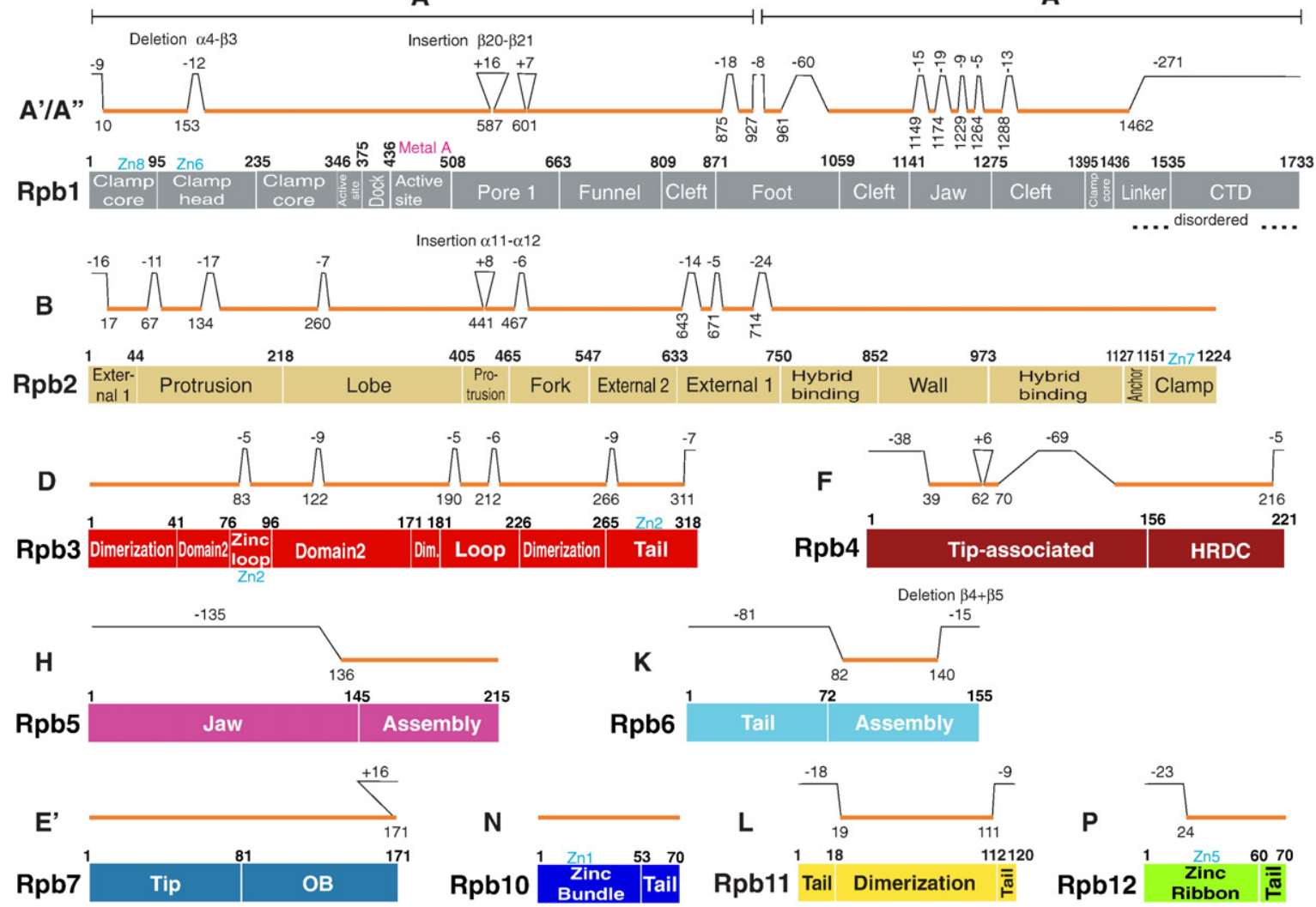

Figure 2. Conservation of RNAP II regions in P.fu RNAP. The domain organization of RNAP subunits is shown as diagrams (compare Table 1). ${ }^{2}$ An orange bar above the diagrams indicates conserved regions. Insertions and deletions exceeding four amino acid residues are depicted. (For details, see Supplemental Data Figure S1.) Yeast RNAP II subunits Rpb8 and Rpb9 have no homologue in P.fu RNAP. 
Rpb4/7 in RNAP II (Figure 1(d)). However, EM density is largely lacking for the outermost domains of the subcomplex F/E', the OB and HRDC domains (Figure 1(d)), indicating their mobility. Indeed, the OB domain is the most flexible region of RNAP II according to normal mode analysis (not shown), and the HRDC domain is mobile in RNAP III. ${ }^{18,19}$

In conclusion, the first structure of an archaeal RNAP identified similarities to the related structure of eukaryotic RNAP II, but also revealed unique deviations. The main finding is that the archaeal enzyme can largely be regarded as a truncated version of RNAP II. P.fu RNAP mainly lacks parts that are peripheral in RNAP II, including two small subunits and several surface domains and loops. Finally, our results provide the basis for structural studies of archaeal RNAP complexes that should provide significant mechanistic insights into eukaryotic transcription as well.

\section{Acknowledgements}

We thank Anass Jawhari and other members of the Cramer laboratory for help. We thank Michael Forchheim for help. We thank Thorsten Mielke for help with EM data collection. P.C. was supported by the Deutsche Forschungsgemeinschaft, the Sonderforschungsbereich SFB646, the Center for integrated Protein Science CiPS ${ }^{\mathrm{M}}$, and the Fonds der chemischen Industrie. R.B. was supported by the Deutsche Forschungsgemeinschaft and the Sonderforschungsbereiche SFB646 and SFB594. EM data were collected at the USN (UltraStructureNetwork) supported by the European Union and the Senatsverwaltung für Wissenschaft, Forschung und Kultur Berlin.

\section{Supplementary Data}

Supplementary data associated with this article can be found, in the online version, at doi:10.1016/ j.jmb.2007.08.066

\section{References}

1. Zhang, G., Campbell, E. A., Minakhin, L., Richter, C., Severinov, K. \& Darst, S. A. (1999). Crystal structure of Thermus aquaticus core RNA polymerase at $3.3 \AA$ resolution. Cell, 98, 811-824.

2. Cramer, P., Bushnell, D. A. \& Kornberg, R. D. (2001). Structural basis of transcription: RNA polymerase II at 2.8 angstrom resolution. Science, 292, 1863-1876.

3. Murakami, K. S., Masuda, S. \& Darst, S. A. (2002). Structural basis of transcription initiation: RNA polymerase holoenzyme at $4 \AA$ resolution. Science, 296, 1280-1284.

4. Vassylyev, D. G., Sekine, S., Laptenko, O., Lee, J., Vassylyeva, M. N., Borukhov, S. \& Yokoyama, S. (2002). Crystal structure of a bacterial RNA polymerase holoenzyme at $2.6 \AA$ resolution. Nature, 417, 712-719.
5. Armache, K.-J., Mitterweger, S., Meinhart, A. \& Cramer, P. (2005). Structures of complete RNA polymerase II and its subcomplex Rpb4/7. J. Biol. Chem. 280, 7131-7134.

6. Cramer, P. (2002). Multisubunit RNA polymerases. Curr. Opin. Struct. Biol. 12, 89-97.

7. Todone, F., Brick, P., Werner, F., Weinzierl, R. O. \& Onesti, S. (2001). Structure of an archaeal homolog of the eukaryotic RNA polymerase II RPB4/RPB7 complex. Mol. Cell, 8, 1137-1143.

8. Langer, D., Hain, J., Thuriaux, P. \& Zillig, W. (1995). Transcription in archaea: similarity to that in eukarya. Proc. Natl Acad. Sci. USA, 92, 5768-5772.

9. Thomm, M. (2007). Transcription: mechanism and regulation. In Archaea: Molecular and Cellular Biology (Caviccioli, R., ed), pp. 139-157, ASM Press, Washington, DC.

10. Geiduschek, E. P. \& Ouhammouch, M. (2005). Archaeal transcription and its regulators. Mol. Microbiol. 56, 1397-1407.

11. Bell, S. D., Magill, C. P. \& Jackson, S. P. (2001). Basal and regulated transcription in Archaea. Biochem. Soc. Trans. 29, 392-395.

12. Meinhart, A., Blobel, J. \& Cramer, P. (2003). An extended winged helix domain in general transcription factor E/IIEalpha. J. Biol. Chem. 278, 48267-48274.

13. Kosa, P., Ghosh, G., DeDecker, B. s. \& Sigler, P. B. (1997). The 2.1- $\AA$ crystal structure of an archaeal preinitiation complex: TATA-box-binding protein/ transcription factor (II)B core/TATA-box. Proc. Natl Acad. Sci. USA, 94, 6042-6047.

14. Hethke, C., Geerling, A. C., Hausner, W., de Vos, W. M. \& Thomm, M. (1996). A cell-free transcription system for the hyperthermophilic archaeon Pyrococcus furiosus. Nucl. Acids Res. 24, 2369-2376.

15. Chen, H. T. \& Hahn, S. (2003). Binding of TFIIB to RNA polymerase II: mapping the binding site for the TFIIB zinc ribbon domain within the preinitiation complex. Mol. Cell, 12, 437-447.

16. Bushnell, D. A., Westover, K. D., Davis, R. E. \& Kornberg, R. D. (2004). Structural basis of transcription: an RNA polymerase II-TFIIB cocrystal at 4.5 Angstroms. Science, 303, 983-988.

17. Minakhin, L., Bhagat, S., Brunning, A., Campbell, E. A., Darst, S. A., Ebright, R. H. \& Severinov, K. (2001). Bacterial RNA polymerase subunit omega and eukaryotic RNA polymerase subunit RPB6 are sequence, structural, and functional homologs and promote RNA polymerase assembly. Proc. Natl Acad. Sci. USA, 98, 892-897.

18. Jasiak, A. J., Armache, K. J., Martens, B., Jansen, R. P. \& Cramer, P. (2006). Structural biology of RNA polymerase III: subcomplex C17/25 X-ray structure and 11 subunit enzyme model. Mol. Cell, 23, 71-81.

19. Fernandez-Tornero, C., Bottcher, B., Riva, M., Carles, C., Steuerwald, U., Ruigrok, R. W. et al. (2007). Insights into transcription initiation and termination from the electron microscopy structure of yeast RNA polymerase III. Mol. Cell, 25, 813-823.

20. Frank, J., Radermacher, M., Penczek, P., Zhu, J., Li, Y., Ladjadj, M. \& Leith, A. (1996). SPIDER and WEB: processing and visualization of images in 3D electron microscopy and related fields. J. Struct. Biol. 116, 190-199.

21. Chen, J. Z. \& Grigorieff, N. (2007). SIGNATURE: a single-particle selection system for molecular electron microscopy. J. Struct. Biol. 157, 168-173.

22. Kuhn, C.-D., Geiger, S. R., Baumli, S., Gartmann, M., Gerber, J., Jennebach, S. et al. (2007). Functional architecture of RNA polymerase I. Cell, 131, 1-13. 